\section{Bioética e Educação na Formação de Profissionais de Saúde}

\author{
Braga, Cristina \\ Uninove
}

Curado, Guilherme Hildebrando

EESCSP (Nursing School of Santa Casa)

guidelbrando@yahoo.com.br

Medeiros, Donato José

UMC (University of Mogi das Cruzes), CBECCESP (Brazilian Association of Education, Science and Culture of the State of São Paulo) EESCSP

\section{Santos, Ben Hesed}

UNG (University of Guarulhos), CBECCESP and EESCSP

Pontes, Victoria Caroline Bottino

EESCSP (Santa Casa School of Nursing)

PALAVRAS-CHAVE: Bioética; Educação Libertadora; Formação na Saúde.

Introdução: Veiculamos a Educação Libertadora, teoria proposta por Paulo Freire, para construção de uma sociedade democrática, justa, pluralista, promovendo equidade social para sujeitos coletivos e individuais, respeitando e aplicando na prática os Direitos Humanos através das experiências vividas no ambiente da sala de aula. Portanto essa educação deve ser capaz de desencadear uma visão do todo, de interdependência e transdisciplinaridade além de possibilitar a construção de redes de mudanças sociais que admitam práticas pedagógica, ética, crítica, reflexiva e transformadora, ultrapassando os limites puramente técnicos para efetivamente alcançar a formação do homem como ser histórico inscrito na dialética da ação-reflexão-ação. Os princípios da bioética, sendo eles autonomia, justiça, não maleficência e beneficência possibilita no ensino aprendizagem atender objetivos, desafios e problemáticas sociais de forma holística respeitando os pareceres da Organização Mundial da Saúde no que define saúde como relativo estado de bem estar biológico psicológico social e não meramente ausência física da doença, além de atender os preceitos dos Direitos Humanos no que se refere a diversidades sociais como cor, etnia, gênero e orientação sexual, atuar nas desigualdades sociais como pobreza, analfabetismo, fome, desemprego, e variáveis de saúde como renda, moradia, acesso à saúde, educação, saneamento básico, emprego, transporte, acesso à cultura, lazer sendo eixos fundamentais que garantem a saúde social visto que durante séculos foram realizadas políticas de exclusão no Brasil. Objetivo: Refletir sobre metodologias ativas utilizadas na formação de profissionais da saúde de nível médio técnico assim como desafios enfrentados para construção de autonomia como cidadão, através de uma proposta emancipatória. Método: Revisão sistemática da literatura, realizada em bases de dados eletrônicas (Medline/PubMed, Lilacs, Ovid, Science Direct, BioMed Central e High Wire). Conclusão: Desde os anos 90 a bioética de intervenção assume o compromisso de contribuir para mudança social e politizar o discurso para defender as ações do trabalhador em saúde conscientizando-se a fim de garantir a inclusão social por meio de políticas públicas de saúde através dos princípios e diretrizes do Sistema Único de Saúde norteado pela Constituição de 1988 e Lei Orgânica da Saúde 8080/90 a todos os usuários. O histórico de saúde no Brasil, visto sempre na periferia do sistema socioeconômico, sendo excludente até a redemocratização em 1988, tratada como comércio por iniciativas privadas e o Estado, gerando competição com a máquina pública para obtenção de lucros, tem como consequência alienação do trabalhador devido a exploração do trabalho, sendo um dos problemas atuais que desafia o educador, partindo do preceito que parte desses também estão em busca de sua autonomia devido grande parte pertencem ao grupo de trabalhadores alienados. A proposta de construção do estudo de caso como parte de metodologia ativa permite emancipação do pensamento dentro do contexto biopsicossocial atendendo premissas anteriormente estabelecidas. $O$ estudo de caso deve apresentar problemas sociais próximos da realidade com variáveis do conceito de saúde em seu termo amplificado para gerar ação-reflexão-ação, o educando e o educador se aproximam do real contexto social possibilitando seu reconhecimento, sendo assim sujeitos ativos na aprendizagem. O principal instrumento para os educandos serem reconhecidos como ativadores da integração é o ensino pela problematização e organização curricular em torno da Aprendizagem Baseada em Problemas.

\section{REFERÊNCIAS}

[1] COTTA MM, GOMES AP, MAIA TM, MAGALHÃES KA, MARQUES ES, SIQUEIRA-BATISTA R. Pobreza, Injustiça, e Desigualdade Social: repensando a formação de Profissionais de Saúde. Rev Bras de educação médica. 2007, 29 (1): 279-83

[2] MITRE SM, SIQUEIRA-BATISTA R, GIRARDI-DEMENDONÇA JM, MORAIS-PINTO NM, MEIRELLES CAB, PINTO-PORTO C MOREIRA T, HOFFMANN LMA. Metodologias ativas de ensino-aprendizagem na formação profissional em saúde: debates atuais. Rev Ciência \& Saúde Coletiva, 2008 13(Sup 2):2133-2144.

[3] POLIGNANO MV. História das Polícicas Públicas de Saúde no Brasil. Uma pequena revisão. 2007, Rio de Janeiro p 1-33. 